\title{
Replacement of the ascending aorta in bicuspid aortic valve disease: Where do we draw the line?
}

\author{
Thoralf M. Sundt III, MD
}

During the past decade, there has been increasing attention to the risk of aortic complications associated with bicuspid aortic valve (BAV) disease. BAV is a curious experiment of nature in the biology of aortic aneurysmal disease and, therefore, has been the subject of considerable scientific investigation. It is widely recognized that BAV disease is a heritable condition transmitted in an autosomal dominant fashion with incomplete penetrance. ${ }^{1,2}$ The occurrence of an associated aortopathy independent of functional valve disease is also well documented. ${ }^{3-7}$ Although the associated aneurysmal dilatation of the ascending aorta has been thought by many to be a hemodynamic effect, analogous to post-stenotic dilatation, it is increasingly recognized that this is an inherent abnormality of the aorta. ${ }^{8}$ Significant ascending aortic enlargement is present in $30 \%$ to $60 \%$ of patients with BAV, and in many instances, particularly when BAV is associated with aortic insufficiency, the aortic valve annulus is significantly enlarged, as may be the sinuses of Valsalva. ${ }^{5,9-11}$

It has also long been recognized that patients with BAV are overrepresented in autopsy studies of dissection, making up as many as $10 \%$ of these individuals. ${ }^{12}$ Because $\mathrm{BAV}$ is thought to occur in the general population at a frequency of $1 \%$, this is a significant overrepresentation. Of note, the diameter of these BAV-associated aortas before dissection is, of course, unknown. In addition, progressive enlargement of the ascending aorta after aortic valve replacement has been documented, ${ }^{13}$ as has excess longterm mortality among patients undergoing aortic valve replacement for bicuspid disease compared with trileaflet valves. ${ }^{14}$ Accordingly, an increasingly aggressive approach to the surgical replacement of the ascending aorta at the time of aortic valve replacement in the presence of BAV has been advocated. Given the evidence from multiple studies that aortic dissection may occur at dimensions less than $5 \mathrm{~cm}$, including among patients with BAV, current American College of Cardiology/American Heart Association guidelines recommend concomitant ascending aortic

\footnotetext{
From the Division of Cardiovascular Surgery, Mayo Clinic, Rochester, Minn. Disclosures: Thoralf M. Sundt III receives grant/research support from Atricure, Inc, Boehringer Ingelheim, Bolton Medical, Edwards Lifesciences, Jarvik Heart, Inc, Sorin Group/Crabomedics, St. Jude Medical, Throatec Corporation, Ventracor, Inc, and Gore \& Associates, Inc.

Received for publication April 30, 2010; accepted for publication Aug 27, 2010. Address for reprints: Thoralf M. Sundt III, MD, Mayo Clinic, 200 First Street, SW, Rochester, MN 55905 (E-mail: Sundt.thoralf@mayo.edu).

J Thorac Cardiovasc Surg 2010;140:S41-4

$0022-5223 / \$ 36.00$

Copyright (c) 2010 by The American Association for Thoracic Surgery doi:10.1016/j.jtcvs.2010.08.053
}

replacement at the time of aortic valve replacement for BAV if the ascending aorta exceeds $4.5 \mathrm{~cm}$ with the subtle assumption that in experienced hands this can be accomplished at little incremental risk. ${ }^{15}$

The more difficult question arises among patients whose BAV is functioning well, but who demonstrate only moderate degrees of aortic dilatation. At what diameter does the aorta itself become an indication for surgical repair? There is broad agreement for all patients with ascending aortic aneurysms that aortic dilatation to $6 \mathrm{~cm}$ or greater strongly supports surgical repair, and an almost unanimous view that surgical intervention is prudent at a diameter of 5.5 $\mathrm{cm} .{ }^{16}$ Some have advocated earlier repair at $5 \mathrm{~cm}$ to provide an additional margin of safety. But what about dimensions less than $5 \mathrm{~cm}$ ? At what point do we draw the line? When does the treatment become worse than the disease?

The implications of ever lower diameter criteria for replacement of the ascending aorta associated with BAV are profound. Given an incidence of $1 \%$ among the 300 million citizens living in the United States today, any recommendation regarding the ascending aorta in the presence of BAV affects an enormous number of individuals. ${ }^{17}$ Beyond the statistical impact, the emotional force is great as well. As anxiety concerning the risk of dissection among patients with only moderate dilatation of the ascending aorta increases, more women of child-bearing age women come to medical attention asking about the safety of pregnancy. Should a newlywed wishing to start a family and found to have an ascending aorta of $4.5 \mathrm{~cm}$ be advised that it is unsafe for her to do so? Is close cardiologic monitoring satisfactory, or is she prohibited from having children? Do the data really support the notion that the risks of dissection are greater at a given aortic diameter when associated with BAV?

To be sure, aortic dissection can occur among patients with BAV at dimensions less than $5 \mathrm{~cm}$, but the same is true of the general population. ${ }^{18}$ But the mean diameter of the ascending aorta progressing to dissection in the setting of BAV in the study by Svensson and colleagues ${ }^{19}$ was 6 $\mathrm{cm}$, just what we would expect from the general population.

Why do we have so much difficulty in drawing the line between the aorta that can be monitored and the aorta that needs to be replaced? Of course, one problem is the inescapable paradox of making a binary decision in the face of a continuous gradient of risk. Beyond this, there are at least 3 complicating issues: the numerator/denominator problem, the difference between probability and statistics, and the seemingly irresistible urge to equate BAV with Marfan syndrome. 


\section{Risk of Dissection at a Given Diameter}

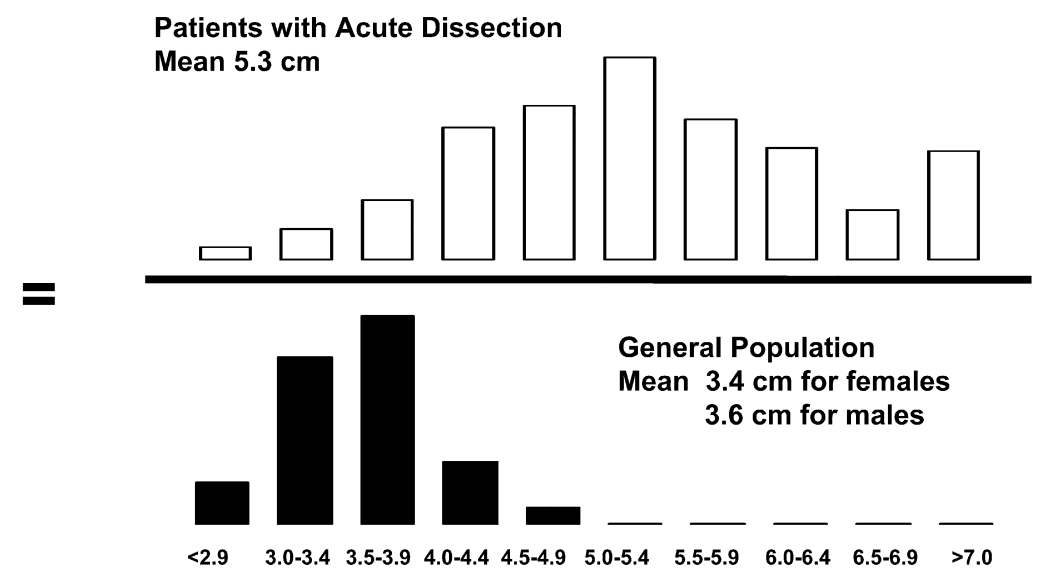

Frequency Distribution of Ascending Aortic Diameter (cm)

FIGURE 1. Calculating the risk of dissection requires knowledge of both the numerator and denominator.

Although aortic dissection at a diameter smaller than $5 \mathrm{~cm}$ is surely alarming, it is also true that the majority of patients have aortas smaller than $5 \mathrm{~cm}$. To calculate the risk of aortic complications, we need not only the numerator, which is to say the cases that come to medical or surgical attention, but also the vast denominator of patients who live happily without complications (Figure 1). Our efforts to screen the public reveal "disease" among this vast denominator, but the clinically relevant question is: What is their risk of complications, and does it exceed the operative risk for ascending aortic replacement? The same numerator/denominator problem is evident in the location of traffic accidents; the majority, likely more than $50 \%$, occur within 5 miles of home, whereas less than $20 \%$ occur more than 20 miles from home. But is it really safer to drive on the freeway? No: We simply spend more time driving close to home- the denominator is greater. As surgeons, we live in the numerator, seeing only those patients who have had complications.

The next challenge is the relationship between statistics and probability, which is to say the relationship between the observed past and the predicted future. We know that, given a dissection, the statistical frequency of BAV is 1 in 10. But given a BAV, what is the probability of future dissection? This is the difference between what we know and what we want to know. The sample space for the former question is all patients with dissection, whereas that for the latter is all patients with BAV. Bayes' Theorem of conditional probability is helpful in estimating this risk given some assumptions (Figure 2). The probability of acute dissection (disease) given BAV (exposure) equals the product of the probability of a BAV given acute dissection and the probability of acute dissection divided by the probability of a BAV. If the probability of BAV given acute dissection is $10 \%$ or $0.1,{ }^{12}$ and the probability of acute dissection is 10 in $100,000^{20}$ with a population frequency of BAV $1 \%$ or 0.01 , we would estimate the probability of acute dissection given a BAV to be 0.001 or $0.1 \%$. Of course this would be the risk of the natural history of the disease given all-comers with BAV, without stratifying by aortic dimensions. Any prophylactic treatment needs to be accomplished at lower risk than this.

Finally, what is the evidence supporting the analogy with Marfan syndrome? There is no question that there are similarities. Both are heritable conditions with associated inherent aortic abnormalities. Elastin loss and fragmentation have been observed in histologic specimens of patients with aneurysms associated with both conditions,${ }^{21}$ as has apoptosis of vascular smooth muscle cells. ${ }^{22}$ Furthermore, histologic specimens have demonstrated a fibrillin deficiency ${ }^{23}$

\section{Bayes Theorem}

$$
P(D / E)=\frac{P(E / D) \times P(D)}{P(E)}
$$

$$
\begin{gathered}
\text { Prob AD given BAV }=\frac{(\text { Prob BAV given AD) (Prob AD) }}{\text { Prob BAV }} \\
P=\frac{(0.1)(0.0001)}{(0.01)}=0.001 \text { or } 0.1 \%
\end{gathered}
$$

FIGURE 2. Bayes' Theorum as applied to prediction of the probability of dissection given a bicuspid aortic valve. $B A V$, Bicuspid aortic valve. 
and increased matrix metalloproteinases and decreased tissue inhibitor of metalloproteinases. ${ }^{24-26}$ What is less clear is the quantitative relationship between the 2. Nonetheless, the urge to make the analogy between BAV disease and Marfan syndrome seems irresistible. Numerous authors have done so, and it is common to find the phrase "BAV and Marfan syndrome" in discussions of aortic disease.

The surgical relevance of this analogy with Marfan syndrome is the recent trend to recommend earlier and earlier surgical intervention among patients with the latter condition. ${ }^{27}$ Again, as in those without Marfan syndrome, dissection can occur in those with Marfan syndrome at aortic diameters less than $5 \mathrm{~cm}^{28}$ This, as well as the advent of valve-sparing options, has encouraged an increasingly aggressive approach such that root replacement is commonly recommended Marfan syndrome when the aorta is $4.5 \mathrm{~cm}$ or less. ${ }^{29}$ These recommendations, however, are based almost exclusively on "expert opinion."

Is BAV comparable to Marfan syndrome? Only a small number of studies have been performed evaluating the natural history of ascending aortic aneurysms in the setting of BAV. Among those that have been done, there is scant evidence of a significantly increased risk of rupture or dissection among those with small aortas. Furthermore, in contrast with Marfan syndrome, data suggest that supracoronary graft replacement of the ascending aorta, leaving behind the sinuses of Valsalva, seldom leads to root aneurysms (Park, unpublished data, 2010). Finally, data from the Mayo Clinic concerning patients undergoing aortic valve replacement for BAV demonstrate overall survival remarkably similar to that predicted for the general population (McKellar, unpublished data). This is in marked contrast with the natural history of unoperated Marfan syndrome, for which the average age of death is approximately 30 years. ${ }^{30}$ Clearly $1 \%$ of the population is not dying at a mean age of 30 years secondary to BAV aortopathy and rupture. Indeed, the most common indication for surgical intervention among patients with BAV in an Olmsted County community-based study was aortic valve replacement, not aortic replacement. ${ }^{31}$ Finally, if one reviews the data presented by the International Registry of Dissection, the frequency of BAV among patients with acute dissection is approximately comparable to Marfan syndrome despite BAV being 100 times more common. ${ }^{18}$

Although surgeons strive to be evidence-based, we are experience-driven. This can lead to faulty reasoning as we practice on the basis of heuristics, not science. The evidence that $\mathrm{BAV}$ is a risk factor for dissection independently of aortic size is scant. BAV is not Marfan syndrome.

\section{References}

1. Cripe L, Andelfinger G, Martin LJ, et al. Bicuspid aortic valve is heritable. JAm Coll Cardiol. 2004;44:138-43.
2. Loscalzo ML, Goh DL, Loeys B, et al. Familial thoracic aortic dilation and bicommissural aortic valve: a prospective analysis of natural history and inheritance. Am J Med Genet A. 2007;143:1960-7.

3. Basso C, Boschello M, Perrone C, et al. An echocardiographic survey of primary school children for bicuspid aortic valve. Am J Cardiol. 2004;93:661-3.

4. Cecconi M, Manfrin M, Moraca A, et al. Aortic dimensions in patients with bicuspid aortic valve without significant valve dysfunction. Am J Cardiol. 2005;95: 292-4.

5. Nistri S, Sorbo MD, Marin M, et al. Aortic root dilatation in young men with normally functioning bicuspid aortic valves. Heart. 1999;82:19-22.

6. Nkomo VT, Enriquez-Sarano M, Ammash NM, et al. Bicuspid aortic valve associated with aortic dilatation: a community-based study. Arterioscler Thromb Vasc Biol. 2003;23:351-6.

7. Hahn RT, Roman MJ, Mogtader AH, Devereux RB. Association of aortic dilation with regurgitant, stenotic and functionally normal bicuspid aortic valves. J Am Coll Cardiol. 1992;19:283-8.

8. McKusick VA. Association of congenital bicuspid aortic valve and Erdheim's cystic medial necrosis. Lancet. 1972;1:1026-7.

9. Morgan-Hughes GJ, Roobottom CA, Owens PE, Marshall AJ. Dilatation of the aorta in pure, severe, bicuspid aortic valve stenosis. Am Heart J. 2004;147: 736-40.

10. Novaro GM, Griffin BP. Congenital bicuspid aortic valve and rate of ascending aortic dilatation. Am J Cardiol. 2004;93:525-6.

11. Sabet HY, Edwards WD, Tazelaar HD, Daly RC. Congenitally bicuspid aortic valves: a surgical pathology study of 542 cases (1991 through 1996) and a literature review of 2,715 additional cases. Mayo Clinic Proc. 1999;74:14-26.

12. Edwards WD, Leaf DS, Edwards JE. Dissecting aortic aneurysm associated with congenital bicuspid aortic valve. Circulation. 1978;57:1022-5.

13. Yasuda H, Nakatani S, Stugaard M, et al. Failure to prevent progressive dilation of ascending aorta by aortic valve replacement in patients with bicuspid aortic valve: comparison with tricuspid aortic valve. Circulation. 2003;108(Suppl 1): II291-4.

14. Borger MA, Preston M, Ivanov J, et al. Should the ascending aorta be replaced more frequently in patients with bicuspid aortic valve disease? J Thorac Cardiovasc Surg. 2004;128:677-83.

15. Bonow RO, Carabello BA, Chatterjee K, et al. 2008 focused update incorporated into the ACC/AHA 2006 guidelines for the management of patients with valvular heart disease: a report of the American College of Cardiology/American Heart Association Task Force on Practice Guidelines (Writing Committee to revise the 1998 guidelines for the management of patients with valvular heart disease) Endorsed by the Society of Cardiovascular Anesthesiologists, Society for Cardiovascular Angiography and Interventions, and Society of Thoracic Surgeons J Am Coll Cardiol. 2008;52:e1-142.

16. Davies RR, Goldstein LJ, Coady MA, et al. Yearly rupture or dissection rates for thoracic aortic aneurysms: simple prediction based on size. Ann Thorac Surg. 2002;73:17-27; discussion 27-8.

17. Guntheroth WG. A critical review of the American College of Cardiology/American Heart Association practice guidelines on bicuspid aortic valve with dilated ascending aorta. Am J Cardiol. 2008;102:107-10. Epub 2008 Apr 22.

18. Pape LA, Tsai TT, Isselbacher EM, et al. Aortic diameter $>$ or $=5.5 \mathrm{~cm}$ is no a good predictor of type A aortic dissection: observations from the International Registry of Acute Aortic Dissection (IRAD). Circulation. 2007;116:1120-7.

19. Svensson LG, Kim KH, Lytle BW, Cosgrove DM. Relationship of aortic crosssectional area to height ratio and the risk of aortic dissection in patients with bicuspid aortic valves. J Thorac Cardiovasc Surg. 2003;126:892-3.

20. Olsson C, Thelin S, Stahle E, et al. Thoracic aortic aneurysm and dissection: in creasing prevalence and improved outcomes reported in a nationwide populationbased study of more than 14,000 cases from 1987 to 2002. Circulation. 2006;114: 2611-8. Epub 2006 Dec 4.

21. Bauer M, Pasic M, Meyer R, et al. Morphometric analysis of aortic media in patients with bicuspid and tricuspid aortic valve. Ann Thorac Surg. 2002;74:58-62.

22. de Sa M, Moshkovitz Y, Butany J, David TE. Histologic abnormalities of the ascending aorta and pulmonary trunk in patients with bicuspid aortic valve disease: clinical relevance to the Ross procedure. J Thorac Cardiovasc Surg. 1999;118: 588-94.

23. Fedak PW, de Sa MP, Verma S, et al. Vascular matrix remodeling in patients with bicuspid aortic valve malformations: implications for aortic dilatation. J Thorac Cardiovasc Surg. 2003;126:797-806.

24. Boyum J, Fellinger EK, Schmoker JD, et al. Matrix metalloproteinase activity in thoracic aortic aneurysms associated with bicuspid and tricuspid aortic valves. $J$ Thorac Cardiovasc Surg. 2004;127:686-91. 
25. Ikonomidis JS, Jones JA, Barbour JR, et al. Expression of matrix metalloproteinases and endogenous inhibitors within ascending aortic aneurysms of patients with Marfan syndrome. Circulation. 2006;114(1 Suppl): I365-70.

26. Ikonomidis JS, Jones JA, Barbour JR, et al. Expression of matrix metalloproteinases and endogenous inhibitors within ascending aortic aneurysms of patients with bicuspid or tricuspid aortic valves. J Thorac Cardiovasc Surg. 2007;133: 1028-36. Epub 2007 Feb 26.

27. Milewicz DM, Dietz HC, Miller DC. Treatment of aortic disease in patients with Marfan syndrome. Circulation. 2005;111:e150-7.
28. Gott VL, Greene PS, Alejo DE, et al. Replacement of the aortic root in patients with Marfan's syndrome. N Engl J Med. 1999;340:1307-13.

29. Kim SY, Martin N, Hsia EC, et al. Management of aortic disease in Marfan syndrome: a decision analysis. Arch Intern Med. 2005;165:749-55.

30. Finkbohner R, Johnston D, Crawford ES, et al. Marfan syndrome. Long-term survival and complications after aortic aneurysm repair. Circulation. 1995;91: 728-33.

31. Michelena HI, Desjardins VA, Avierinos JF, et al. Natural history of asymptomatic patients with normally functioning or minimally dysfunctional bicuspid aortic valve in the community. Circulation. 2008;117:2776-84. 